\title{
Üretim Parametrelerinin Hidroksiapatit Tozlarının Özellikleri ve Kaplama Kalitesi Üzerindeki Etkilerinin İncelenmesi
}

\author{
Önder ALBAYRAK ${ }^{* 1}$, Mehmet İPEKOĞLU ${ }^{2}$, Sabri ALTINTAŞ ${ }^{3}$ \\ ${ }^{1}$ Mersin Üniversitesi, Mühendislik Fakültesi, Makine Mühendisliği Bölümü, Mersin \\ ${ }^{2}$ Türk-Alman Üniversitesi, Mühendislik Fakültesi, Makine Mühendisliği Bölümü, İstanbul \\ ${ }^{3}$ Boğaziçi Üniversitesi, Mühendislik Fakültesi, Makine Mühendisliği Bölümü, İstanbul
}

Geliş tarihi: $30.04 .2019 \quad$ Kabul tarihi: 20.12 .2019

$\ddot{\mathbf{O z}}$

Biyomedikal uygulamalarda yaygın olarak kullanılan metal implantlar, çevre dokularla hızlı ve sağlıklı entegrasyonun sağlanması amacıyla, biyouyumluluğu yüksek malzemeler ile kaplanmaktadır. Kaplama malzemeleri arasında, yüksek biyouyumluluğa sahip olması ve kemiğin anorganik fazına büyük ölçüde benzer özellikler taşıması nedeniyle, hidroksiapatit özellikle tercih edilmektedir. Gerçekleştirilen bu çalışmada, kaplama amacıyla kullanılmak üzere asit-temelli sentez yöntemiyle nano boyutta hidroksiapatit (HA) tozları üretilmiş, elde edilen HA tozları elektroforetik depozisyon yöntemi ile Ti6Al4V metal ana yapı üzerine kaplanmıştır. HA sentezi aşamasında uygulanan reaksiyon sıcaklığı ve yaşlandırma süresi parametrelerinin üretilen tozların parçacık boyutu, toz morfolojisi ve isıl kararlılığı üzerindeki etkileri incelenmiş; kullanılan tozların özelliklerinin sinterleme aşaması öncesinde gerçekleştirilen kaplamalarda çatlak oluşumuna etkileri belirlenmiş̧ir. Yapılan deneyler sonucunda reaksiyon sıcaklığı ve yaşlandırma parametrelerinin, HA fazı oluşumu ve HA'nin yüksek sıcaklıktaki kararlılığ1 üzerinde belirgin bir etkisi olmadığı görülmüş̧ür. $1200{ }^{\circ} \mathrm{C}$ 'de gerçekleştirilen sinterleme işleminin, $1000{ }^{\circ} \mathrm{C}^{\prime}$ de gerçekleştirilen sinterleme işlemine kıyasla HA'nin 1 sıl dekompozisyonuna olumsuz bir etkisi olmadığı belirlenmiş, bu nedenle kaplama dayanımını arttırmak amacıyla sinterleme işleminin $1200^{\circ} \mathrm{C}^{\prime}$ de gerçekleştirilmesinin mümkün olduğu sonucuna ulaşılmıştır. Üretilen HA tozlarının yaşlandırma süresinin artmasıyla, sinterleme öncesi çatlak oluşumunda belirgin bir azalma olduğu gözlemlenmiştir.

Anahtar Kelimeler: Hidroksiapatit, Parçacık boyutu, Toz morfolojisi, Isıl kararlılık, Yaşlandırma, Kaplama

\footnotetext{
*Sorumlu yazar (Corresponding author): Önder ALBAYRAK, albayrakonder@mersin.edu.tr
} 


\title{
Investigation of the Effects of Production Parameters on the Hydroxyapatite Powder Properties and Coating Quality
}

\begin{abstract}
Metal implants that have been widely used in biomedical applications are coated with materials having superior biocompatibility in order to facilitate fast and successful integration with the surrounding tissue. Hydroxyapatite (HA) is especially preferred among the coating materials having a high biocompatibility and similar properties to the organic phase of bone. In this study, nano sized HA powder was produced using acid-base method in order to be used as coating material. Produced powders were coated on Ti6Al4V metal substrates using electrophoretic deposition technique. Effects of reaction temperature and aging duration on the particle size, powder morphology and thermal stability of the powders have been investigated, effects of powder properties on the crack formation before sintering have been determined. Experiments showed that reaction temperature and aging duration do not have a significant effect on the formation of HA and high temperature stability of the HA phase. Thermal treatment conducted at $1200{ }^{\circ} \mathrm{C}$ does not have a negative effect on the decomposition of HA compared to the thermal treatment conducted at $1000{ }^{\circ} \mathrm{C}$. Therefore, it is concluded that sintering step which will be conducted in order to obtain coating adhesion may be completed at $1200{ }^{\circ} \mathrm{C}$. It was found that crack formation in the coating before sintering significantly decreases with the increase in aging duration.
\end{abstract}

Keywords: Hydroxyapatite, Particle size, Powder morphology, Thermal stability, Aging, Coating

\section{GíRİş}

Biyomedikal implantlar, hastalık, yaralanma ve benzer sebeplerle oluşan sorunların giderilmesi ve hastanın yaşam kalitesinin artırılması amacıyla tıbbi uygulamalarda uzun süredir yaygın olarak kullanılmaktadır. Doğru ve yerinde gerçekleştirilen implant uygulamaları, hastaların maruz kaldığ fiziksel acıyı ve bundan doğan psikolojik yükü azaltmakta, tıbbi bakıma muhtaç olmaksızın hayatlarını devam ettirmelerine imkan vermektedir. $\mathrm{Bu}$ yönüyle implant uygulamaları tıbbi bir sorunun giderilmesi ve hasta tatmini açısından büyük önem taşımaktadır. Ayrıca, implant uygulamasını gerekli hale getiren tıbbi durumlardan kaynaklanan işgücü kaybının da önüne geçerek hastaların tekrar yeterli ve üretken bir biçimde gündelik hayatlarına dönebilmelerine ve iş hayatına katılabilmelerine imkan vermektedir. $\mathrm{Bu}$ nedenlerden ötürü implant uygulamaları, hem hasta ve hasta yakınları hem de toplum ve ekonomik hayat açısından önem arz etmektedir. İmplantların sahip olduğu bu yaygın etkiler nedeniyle implant üretimine yönelik araştırmalar hız kazanmakta, elde edilen gelişmeler neticesinde implant üretimi artmakta ve buna bağli olarak implant sektörü kayda değer biçimde büyümektedir. Barındırdığı ileri teknoloji, sahip olduğu katma değer, ihracat potansiyeli ve dış bağımlılığı azaltma konularında implant sektörü ülkemiz için de giderek artan ölçüde önem kazanmaktadır. $\mathrm{Bu}$ yönüyle implantların geliştirilmesi ve ticarileştirilmesi konularındaki araştırma ve çalışmalar ülkemizin stratejik ve ekonomik hedefleriyle örtüşmektedir.

İmplant uygulamaları içerisinde, metal implantlar önemli bir yer tutmaktadır. Metal implantın başarısı, büyük oranda implantın çevre dokularla entegrasyonuna bağlıdır. Bu nedenle, implantın biyouyumluluğunun arttırılması önem taşımaktadır. Bu amaca yönelik olarak, kullanılan metal implantın, biyouyumlululuğu yüksek bir malzeme ile kaplanarak çevre dokularla hızlı ve uyumlu bir şekilde entegrasyonunun sağlanmasına yönelik çalıșmalar gerçekleştirilmektedir. Sahip oldukları yüksek biyouyumluluk nedeniyle biyoseramikler, kaplama malzemesi olarak yaygın olarak kullanılmaktadır. Biyoseramikler arasında kemiğin anorganik fazına önemli ölçüde benzer 
özellikler taşıması ve bu sayede yüksek biyouyumluluğa sahip olması nedeniyle, hidroksiapatit (HA) kullanımı öne çıkmaktadır.

Ortopedi ve diş implantları gibi yüksek mekanik dayanım gerektiren biyomedikal uygulamalarda Ti, Ti6Al4V ve 316L paslanmaz çelik gibi metal implantlar yaygın olarak kullanılmaktadır [1]. Metal implantların mekanik avantajları ile HA'in biyouyumluluğunu birleştirmek amaciyla, metal implantların HA ile kaplanmasi konusunda kapsamlı çalışmalar yürütülmektedir [2-5]. İmplantların yüksek biyouyumluluğa sahip HA ile kaplanması, implantın kemiğe daha hızlı ve kararlı tutunmasını, kemikle implant arasında güçlü bir bağ oluşturulmasını ve kemik-implant ara yüzeyinde hızlı ve düzenli kemik büyümesini sağlamaktadır. Aynı zamanda metal iyonlarının implanttan çözünerek vücuda geçmesini de önemli oranda önlemektedir.

$\mathrm{HA}, \mathrm{Ca}_{10}\left(\mathrm{PO}_{4}\right)_{6}(\mathrm{OH})_{2}$, kemiğin anorganik fazına kimyasal açıdan önemli ölçüde benzemesi ve bu sayede sahip olduğu yüksek biyouyumluluk sayesinde biyomalzemeler içinde ön plana çıkmaktadır. HA, özellikle kemik ve diş gibi sert dokuların içerisinde toz halde dolgu malzemesi olarak, sinterlenmiş haliyle doğrudan ve metal implantların biyouyumluluğunun arttırılması amacıyla kaplanmalarında kullanılmaktadır [6]. İçinde kemik büyümesi amaçlanan uygulamalarda gözenekli, mekanik dayanımın öne çıktığı uygulamalarda ise yoğun yapıda HA tercih edilmektedir. Araştırma sonuçları yoğun yapıdaki HA'in mekanik dayanımının büyük oranda sinterleme sıcaklığına [7] ve parçacık boyutuna [6] bağlı olduğunu ortaya koymaktadır. Mekanik dayanımın arttırılması ve yoğun yapı elde edilmesi amaciyla gerçekleştirilen sinterleme işlemi esnasında HA, isıl dekompozisyona uğrayıp trikalsiyum fosfata (TCP), $\mathrm{Ca}_{3}\left(\mathrm{PO}_{4}\right)_{2}$, dönüşebilmektedir [8]. pH değeri 4,2'den yüksek ortamlarda kararlı yapısını koruyan HA, vücut içinde çözünmeden kalabilmesine rağmen, TCP söz konusu ortamlarda kararlı yapısını koruyamayıp belirli süre sonra çözünmekte ve vücut tarafindan emilmektedir [9]. $\mathrm{Bu}$ durum, kullanılan HA'in mekanik dayanımını düşürmesi ve aynı zamanda çevre dokularla entegrasyonunu güçleştirmesi nedeniyle implant uygulamalarında tehlike arz etmektedir [10].

Literatürde HA üretimi amaciyla; kimyasal sentez (kimyasal çöktürme), sol-jel, sprey-piroliz, hidrotermal sentez, emülsiyon işlemi ve mekanokimyasal yöntem gibi çok sayıda ve farklı yöntem bildirilmektedir. Ancak günümüzde kullanılan bu yöntemler içerisinde; işlem adımlarının sadeliği, düşük işlem sıcaklığı, ürün kalitesi ve verim açısından kimyasal sentez yöntemi öne çıkmaktadır [11-13]. Sıvı ortamda kimyasal çöktürme yöntemleri içinde asit temelli metot, istenmeyen ürünlerin ortaya çıkmaması, HA haricinde yalnızca su oluşması dolayısıyla öne çıkmaktadır [12,14,15] (Eşitlik 1):

$$
10 \mathrm{Ca}(\mathrm{OH})_{2}+6 \mathrm{H}_{3} \mathrm{PO}_{4} \rightarrow \mathrm{Ca}_{10}\left(\mathrm{PO}_{4}\right)_{6}(\mathrm{OH})_{2}+18 \mathrm{H}_{2} \mathrm{O}
$$

Söz konusu metodun başarısındaki en önemli etken, reaksiyon sirasinda $\mathrm{pH}$ seviyesinin hassas biçimde kontrol edilmesidir. $\mathrm{pH}$ değerinin 9'un altına inmesi durumunda kalsiyum monofosfat, 7 'nin altına inmesi durumunda kalsiyum dihidrat oluşmaktadır [16]. Bu amaçla, reaksiyon süresince çözeltinin $\mathrm{pH}$ değerinin sürekli olarak gözlemlenmesi ve ayarlanması önemlidir.

Literatürde kimyasal sentez yöntemi ile HA eldesinde, reaksiyon süresi [17], reaksiyon sıcaklığı [17], asit ekleme hızı [16], çökelti kurutma hızı [16] parametrelerinin, elde edilen HA tozunun parçacık boyutu ve morfolojisi üzerinde belirgin etkileri olduğu rapor edilmiştir. Saeri ve arkadaşları [17], yaşlandırma sonucunda parçacık boyutunda artış olduğunu ve üretilen HA parçacık boyutlarının birbirlerine yaklaştığını gözlemlemiş, ayrıca çökeltme işleminin verimliliğinin arttığını belirtmişlerdir. Wei [18], uzun yaşlandırma süreleri ve ardından isıtma işlemleri ile HA tozunun şekilsel ve boyutsal benzerliğinin arttığını, bu şekilde elde edilen homojen morfolojide tozların kullanımıyla yapilan elektroforetik kaplamanın kalitesinin arttığını vurgulamaktadır.

Metal implant yüzeylerine biyoseramik ve özel olarak HA kaplama konusunda değişik yöntemler uygulanmasına rağmen elektroforetik depozisyon 
yöntemi en etkili ve verimli yöntemlerden birisidir [19]. Bu yöntem, kaplama düzeneğinin kurulumundaki kolaylık, düşük ekipman maliyeti ve implantlarda sıklıkla karşılaşılan kompleks geometrideki yapıların kaplanmasındaki belirgin avantajlarıyla öne çıkmaktadır. Aynı zamanda yaklaşık $1 \mathrm{~mm} /$ dak gibi yüksek hızlarda kaplama yapılmasina imkan vererek ticari olarak da uygulanabilir bir üretim yöntemi ortaya koymaktadır [19]. Elektroforetik depozisyon parametrelerinin, kaplamada kullanılan parçacıkların boyutunun ve şekillerinin doğru biçimde ayarlanması ile kaplama morfolojisinin kontrolü sağlanabilmektedir. Kaplama süresi ve kaplama voltajı gibi parametrelerin değiştirilmesi ile kaplama kalınlığı istenilen şekilde ayarlanabilmektedir $[18,19]$.

Elektroforetik depozisyon, doğru akımla elde edilen elektrik alanının kaplama süspansiyonuna uygulanmasıyla, süspansiyon içindeki kaplama malzemesinin kaplama yüzeyine hareketini ve tutunmasını sağlayan bir kaplama yöntemi olup; iki aşamalı koloidal bir işlemdir. İlk aşamada, kararlı süspansiyon içerisinde elektriksel olarak yüklenmiş seramik parçacıklar, uygulanan elektrik alanının etkisiyle elektrotlardan birine doğru hareket ederler. İkinci aşamada ise bu parçacıklar kaplanmak istenen metal yapı üzerine tutunarak kaplamayı meydana getirirler [20,21].

Elektroforetik depozisyon yöntemiyle metal implantın yüzeyinde oluşturulan HA tabakanın bağlanma dayanımının artırılması amacıyla sinterleme işlemi gerekli olmaktadır. Mekanik dayanımı arttırmak amacıyla uygulanan sinterleme işlemi, doğası gereği bir takım sorunları da kaçınılmaz olarak beraberinde getirmektedir. İlk olarak, sinterleme aşamasında maruz kalınan yüksek sıcaklıklar nedeniyle kaplama malzemesi olan HA tabakasında 1s1 dekompozisyon gözlemlenebilmekte [22,23], bu durum kaplama kalitesini düşürerek kaplama dayanımını olumsuz etkilemektedir. Bu durumun, yalnızca HA'in isıl kararlılı̆g ile ilgili olmayıp sinterleme işleminin gerçekleştirildiği yüksek sıcaklıklarda metal yüzeyden HA tabakaya doğru meydana gelen olas1 iyon transferini de pekiştirdiği düşünülmektedir. Böylece sinterleme sonrasında, kaplamayı meydana getiren HA tabakasında dekompozisyon ve metalden kaynaklı yabancı iyonlar gözlenebilmektedir. Ayrıca sinterleme sirasında HA tabakasında meydana gelen büzüşmeler çatlak oluşumuna sebebiyet vermektedir. Buna ek olarak kaplanan metal yüzey ile kaplama malzemesi olan HA'in isıl genleşme katsayıları arasındaki farklılık, sinterleme işlemindeki ısınma ve soğuma döngüsü sırasında çatlak oluşumuna zemin hazırlamaktadır $[18,23,24]$.

Yürütülen bu çalışmada kaplama işleminde kullanılacak olan tozların sentezlenmesi aşamasında uygulanan parametrelerin, mümkün olduğunca düşük oranda çatlak içeren bir kaplama eldesi üzerindeki etkileri incelenmiş; çatlak oluşumunu kontrol etmeye yönelik olarak uygun sentezleme parametreleri belirlenmiştir. Üretilen kaplamalarda meydana gelen çatlak oluşumu, kaplama kalitesini doğrudan etkilemekte; implantasyona uygun bir kaplama eldesi ancak homojen ve çatlaksız bir kaplama ile mümkün olabilmektedir. Salt kaplama işlemi, mekanik olarak dayanıklı bir kaplama için yeterli olmadığından, gerçekleştirilen kaplamanın dayanımı kaplama işlemini takibeden sinterleme işlemi ile sağlanmaktadır. Sinterleme aşamasında oluşan çatlaklar, kaplama kalitesini etkilemekte ve kullanılabilir nitelikte bir kaplama üretimini güçleştirmektedir. Bunu önlemek amacıyla sinterleme öncesinde, mümkün olduğunca az çatlak içeren bir kaplama elde edilmesi ve bu kaplamada oluşan çatlakların kontrolüne yönelik deneyler gerçekleştirilmiştir.

\section{MATERYAL VE METOT}

\subsection{Kaplamada Kullanılacak Nanoboyutta HA Sentezi ve Karakterizasyonu}

Gerçekleştirilen çalışmada, asit temelli yöntem kullanılarak HA sentezinde kalsiyum kaynağ 1 olarak $\mathrm{Ca}(\mathrm{OH})_{2}(\sim \% 99$, Merck, Almanya), fosfat kaynağ 1 olarak $\mathrm{H}_{3} \mathrm{PO}_{4}$ (\%85, Merck, Almanya) kullanılmıştır $[18,25]$. İlk olarak, 5,0 $\mathrm{g} \mathrm{Ca}(\mathrm{OH})_{2}$ kullanılarak $200 \mathrm{ml}$ deiyonize su içerisinde süspansiyon hazırlanmıştır. Hazırlanan süspansiyon 1sitıc1lı manyetik karıştırıcı üzerinde farklı sabit sicaklıklarda $\left(40,60,80,100{ }^{\circ} \mathrm{C}\right)$ 
bekletilmiştir. Isıtıcılı manyetik karıștırıcı üzerinde sabit hızda karıştırma işlemi devam ederken, çözelti pH'ının 9,5'in altına düşmemesine özen gösterilerek, 4,669 g siv1 $\mathrm{H}_{3} \mathrm{PO}_{4}$ yavaş biçimde $\mathrm{Ca}(\mathrm{OH})_{2}$ süspansiyonuna ilave edilmiştir. Çöktürme işlemi sırasında karıştırma ve yaşlandırma aşamalarının, elde edilen HA tozunun parçacık boyutu üzerindeki etkilerinin belirlenmesi amacıyla farklı karıştırma $(2,10$ ve 20 gün) ve yaşlandırma $(2,10$ ve 20 gün $)$ zamanları uygulanmıştır. Buna göre; hazırlanan numunelerin bazıları tüm yaşlandırma süresi boyunca karıştırılırken diğer numuneler 2 gün boyunca karıştırılmış, ardından karıştırma olmaksızın yaşlandırmaya tabii tutulmuştur. Son olarak elde edilen çökelti her seferinde $500 \mathrm{ml}$ deiyonize su kullanılarak 5 kez "santrifüj (2500 rpm, 4 dakika)dekantasyon-deiyonize su ekleme $(500 \mathrm{ml})$ karıştırma (manyetik karıştırıcı üzerinde 10 dakika)" yapılarak yıkanmıştır. Son santrifüj işlemini takiben çökelti 24 saat boyunca $100{ }^{\circ} \mathrm{C}$ 'de etüvde kurutulmuş ve agat havanda ögütülmüştür. Farklı reaksiyon sıcaklıkları, karıştırma ve yaşlandırma süreleri uygulanarak üretilen HA tozlarına ait parametreler ve bu numunelere ait kodlandırmalar Çizelge 1'de belirtilmiştir.

Çizelge 1. HA sentezlenmesi aşamasında uygulanan reaksiyon sicaklıkları ile karıştırma ve yaşlandırma süreleri

\begin{tabular}{|l|c|c|c|}
\hline $\begin{array}{c}\text { Numune } \\
\text { Adı } 1\end{array}$ & $\begin{array}{c}\text { Reaksiyon } \\
\text { Sicaklığ1 } \\
\left({ }^{\circ} \mathrm{C} \text { ) }\right.\end{array}$ & $\begin{array}{c}\text { Karıştırma } \\
\text { Süresi } \\
\text { (gün) }\end{array}$ & $\begin{array}{c}\text { Yaşlandırma } \\
\text { Süresi } \\
\text { (gün) }\end{array}$ \\
\hline 40C-2K-2Y & 40 & 2 & 2 \\
\hline 40C-2K-10Y & 40 & 2 & 10 \\
\hline 40C-10K-10Y & 40 & 10 & 10 \\
\hline 40C-2K-20Y & 40 & 2 & 20 \\
\hline 40C-20K-20Y & 40 & 20 & 20 \\
\hline 60C-2K-2Y & 60 & 2 & 2 \\
\hline 80C-2K-2Y & 80 & 2 & 2 \\
\hline 100C-2K-2Y & 100 & 2 & 2 \\
\hline
\end{tabular}

Farklı üretim parametreleri kullanılarak üretilen HA tozları, 1sıl dekompozisyon karakteristiklerinin belirlenmesi amacıyla açık atmosfer altında kamara firınında (Protherm PLF 130/45, Türkiye) 2 saat süreyle $5{ }^{\circ} \mathrm{C} /$ dak 1 sitma ve soğutma hizıyla 1000 ve $1200{ }^{\circ} C^{\prime}$ de isitılmış, elde edilen numuneler faz oluşumları ve dekompozisyonun belirlenmesi amacıyla X-ıșın kırınımı (D/MaxUltima, Rigaku, Japonya) kullanılarak incelenmiştir. XRD verileri oda sıcaklığında, $10^{\circ}-60^{\circ}(2 \theta)$ aralığında ve $5 \%$ min tarama hızında elde edilmiştir. Ayrıca üretilen tozların parçacık boyutları, toz morfolojileri ve topaklanma davranışlarının belirlenmesi amacıyla taramalı elektron mikroskobu (Supra 35VP, Leo, Almanya) incelemeleri ve parçacık boyutu ölçümleri (NanoZS model, Malvern, İngiltere) gerçekleştirilmiştir. Parçacık boyutu analizleri, yaş ortamda etanol kullanılarak gerçekleştirilmiştir.

\subsection{Elektroforetik Depozisyon Yöntemi ile Ti6Al4V Üzerine HA Kaplama Eldesi ve Karakterizasyonu}

Elektroforetik kaplama işleminde kullanılacak süspansiyonun hazırlanması için, sentezleme sonrası kurutulmuş olan HA tozları kullanılmıştır. $\mathrm{Bu}$ amaçla $250 \mathrm{ml}$ etanol içerisine 2,5 g HA tozu eklenerek hazırlanan süspansiyon 15 dakika boyunca manyetik karıştırıcıda karıștırılmış, ardından 30 dakika boyunca bekletilmiştir. Bu sürenin ardından dekante edilen süspansiyon kaplama işleminde kullanılmak üzere başka bir behere aktarılmıştır. Bu süspansiyonun, $\mathrm{pH}$ 3-12 aralığında zeta potansiyel ölçümleri (Nano-ZS model, Malvern, İngiltere) yapılarak kaplama için uygun $\mathrm{pH}$ değeri belirlenmiştir. $\mathrm{pH}$ değeri, gerekli miktarda derişik $\mathrm{HCl}$ ve $\mathrm{NaOH}$ çözeltileri kullanılarak ayarlanmış, ardından kaplama işlemi gerçekleştirilmiştir.

Kaplama aşamasında, kaplama süspansiyonu içine birbirlerine paralel olarak daldırılan, güç kaynağına bağlı Ti6A14V elektrotlar arası mesafe $1 \mathrm{~cm}$ olacak şekilde ayarlanmıștır. Elektrotlara 60 sn boyunca $100 \mathrm{~V}$ uygulanmak suretiyle kaplama yapılmıştır. Anot ve katot olarak $25 \times 75 \mathrm{~mm}$ boyutlarında Ti6A14V kullanılmış, süspansiyon içindeki HA tozlarının pozitif yüklü olmasından dolayı, katot üzerinde kaplama gerçekleşmiştir.

Kaplama aşamasında kullanılan elektrotlar, Ti6Al4V plakadan lazer kesme ile elde edilmiş olup; 240-1000 grit arası SiC zımpara kağıtları kullanılarak zımparalanmış, 30 dakika boyunca mutfak deterjanı çözeltisi içerisinde yıkanmış, 
devamında 15 dakika boyunca aseton içinde ve son aşama olarak hacmen $\% 25^{\prime}$ lik nitrik asit (\%65 Merck, Almanya) çözeltisi içerisinde 12 saat boyunca bekletilmiş, ardından destile su ile yıkanmıştır. Elde edilen elektrotlar etanoldan geçirilip kurumaya bırakılmalarının ardından kaplamada kullanılmıştır.

Kaplama sonrasinda elde edilen numuneler $80{ }^{\circ} \mathrm{C}$ 'de 12 saat boyunca kurumaya bırakılmıştır. $\mathrm{Bu}$ şekilde elde edilen HA kaplı Ti6Al4V numuneler, kaplama malzemesi olarak kullanılan HA'in üretim parametrelerinin kaplamada çatlak oluşumuna etkisinin belirlenmesi amacıyla SEM incelemesine tabi tutulmuştur.

\section{BULGULAR}

\subsection{Reaksiyon Sıcaklığının ve Isıl İşı̇emin Üretilen HA Tozlarının Yüksek Sıcaklık Kararlılıklarına Etkilerinin Belirlenmesi}

HA sentezi aşamasında uygulanan reaksiyon sıcaklığının üretilen HA tozlarındaki faz oluşumlarına etkilerinin incelenmesi amacıyla gerçekleştirilen çalışmada, sentezleme 40, 60, 80 ve $100{ }^{\circ} \mathrm{C}$ olmak üzere 4 farklı sicaklıkta gerçekleştirilmiştir. Bu sıcaklık değerlerinde 2 gün süreyle karıştırma ve yaşlandırma işlemi uygulanmıştır. Santrifüj, dekantasyon, kurutma işlemleri ardından elde edilen tozlar 1000 ve $1200{ }^{\circ} \mathrm{C}$ olmak üzere 2 farklı sicaklıkta 1sıl işleme tabi tutulmuşlardır. Reaksiyon sıcaklığ ve farklı sicaklıkta uygulanan 1sıl işlemin HA tozlarının yüksek sıcaklıktaki kararlılıkları üzerindeki etkileri incelenmiştir. $\mathrm{Bu}$ amaçla gerçekleştirilen XRD analizlerinde; tüm numunelerde HA oluşumu tespit edilmiş olup (ICCD PDF No: 00-009-0432); belirgin bir yan faza rastlanmamıştır (Şekil 1 ve 2). Kullanılan ısıl işlem sıcaklıklarının numunelerde HA fazı eldesinde belirgin bir farklılığa yol açmadı $\breve{g}_{1}$ belirlenmiştir. $\mathrm{Bu}$ noktadan hareketle, reaksiyon sicaklığının üretilen tozların faz oluşumları üzerinde belirleyici bir etkisi olmadığı, bu nedenle sentezleme reaksiyonunun düşük sicaklıkta gerçekleştirilmesinin uygun olduğu sonucuna ulaşılmıştır.

Tozların farklı sıcaklıklarda 1sıl işleme tabi tutulması sonucunda, 1sıl işlem sıcaklığı arttıkça HA piklerinin belirginleştiği, dolayısıyla tozların kristalizasyonunun arttığı gözlemlenmiştir (Şekil 1 ve 2). Artan 1sıl işlem sıcaklığ 1 ile öne çıkan bir faz dönüşümüne veya bozunmasına rastlanmamıştır. Faz dönüşümüne veya bozunmasına yol açmayacak şekilde yüksek sıcaklıkta 1sıl işlem uygulanması, kaplama amaciyla kullanılacak tozların bağlanma dayanımı açısından avantaj sağlamaktadır. $\mathrm{Bu}$ nedenle; bir faz dönüşümüne veya bozunmasına yol açmaması sebebiyle, 1200 ${ }^{\circ} \mathrm{C}$ 'de gerçekleştirilecek sinterleme işleminin uygulanabilir olduğu sonucuna ulaşılmıştır.

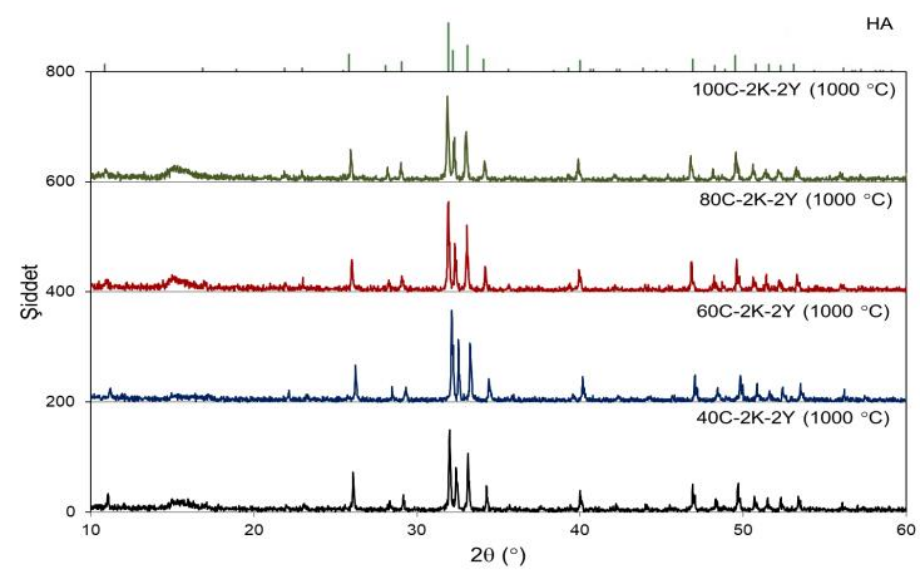

Şekil 1. Farklı reaksiyon sıcaklıklarında üretilen HA tozlarının $1000{ }^{\circ} \mathrm{C}$ 'de 1 ssıl işlem sonrası XRD spektrumları 


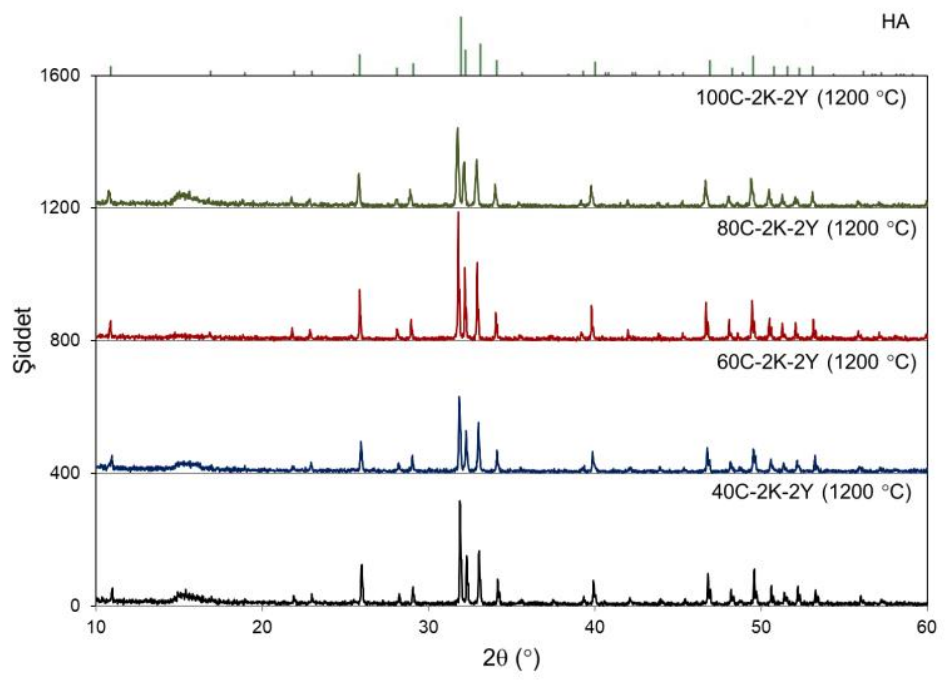

Şekil 2. Farklı reaksiyon sıcaklıklarında üretilen HA tozlarının $1200{ }^{\circ} \mathrm{C}$ 'de 1 sıl işlem sonrası XRD spektrumları

3.2. Farklı Karı̧̧tırma ve Yaşlandırma Sürelerinin Üretilen HA Tozlarının Faz Oluşumlarına Etkilerinin Belirlenmesi

Reaksiyon sıcaklığının ve 1sıl işlemin üretilen HA tozlarının yüksek sicaklı kararlılıklarına etkilerinin incelenmesinden $40{ }^{\circ} \mathrm{C}$ sıcaklığın uygun olduğunun belirlenmesi dolayısıyla çalışmanın geri kalan kısmında sentezleme sicaklığı olarak $40{ }^{\circ} \mathrm{C}$ kullanılmıştır. Sentezleme aşamasında uygulanan farklı karıştırma ve yaşlandırma sürelerinin, elde edilen tozlarda meydana gelen fazlar üzerindeki etkilerinin belirlenmesi amacıyla gerçekleştirilen XRD analizlerinde, tüm numunelerde karakteristik HA pikleri (ICCD PDF No: 00-009-0432) görülmekle birlikte belirgin başka bir faza rastlanmamıştır (Şekil 3). Uygulanan tüm karıştırma ve yaşlandırma süreleri sonucunda HA eldesinin mümkün olduğu görülmüştür.

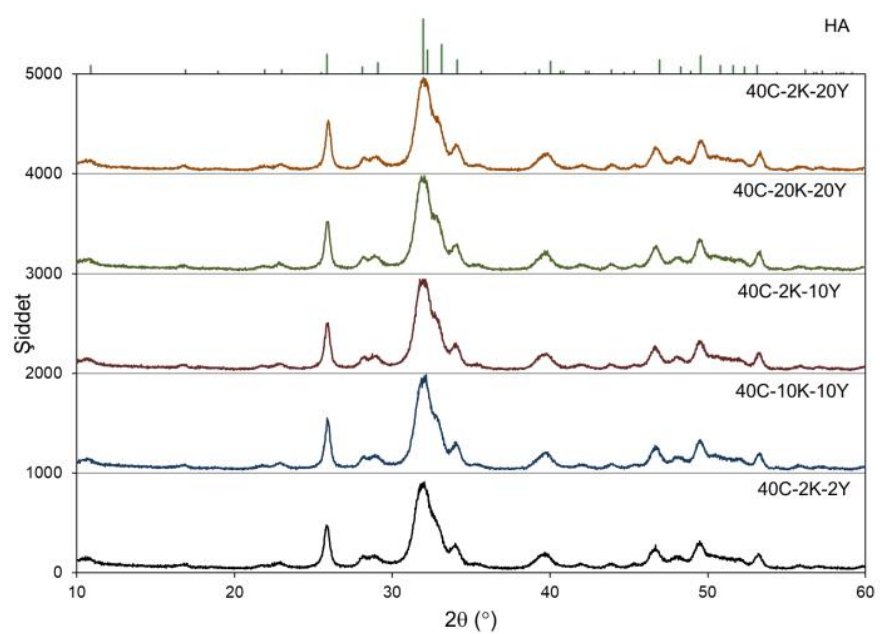

Şekil 3. Farklı karıştırma ve yaşlandırma süreleri uygulanarak sentezlenen HA tozlarına ait XRD spektrumları 
3.3. Isıl İşlemin, Farklı Karıştırma ve Yaşlandırma Süreleri Kullanılarak Üretilen HA Tozlarının Faz Oluşumlarına Etkisinin Belirlenmesi

Farklı karıştırma ve yaşlandırma süreleri uygulanarak (sentezleme sicaklığı: $40^{\circ} \mathrm{C}$ ) üretilen HA tozlarının, bağlanma dayanımının arttırılması amacıyla sinterleme işlemi gerekli olmaktadır. Sinterleme işleminde uygulanan yüksek sıcaklıklar altındaki özelliklerinin belirlenmesi amacıyla, üretilen tozlar, başlık 3.1'de elde edilen bilgiler 1şı̆̆ıında $1200{ }^{\circ} \mathrm{C}$ 'de 1 ssıl işleme tabi tutulmuştur. Sinterlenmiş tozlar üzerinde yapılmış olan XRD analizleri (Şekil 4) 1sıl işlemin tozların kristalizasyonuna olumlu etki ettiğini ortaya koymuştur. Analizlerde tüm numunelerin HA yapısını (ICCD PDF No: 00-009-0432) koruduğu belirlenmiş ancak düşük oranda TCP (ICCD PDF No: 9-169) dönüşümü olduğu gözlemlenmiştir.

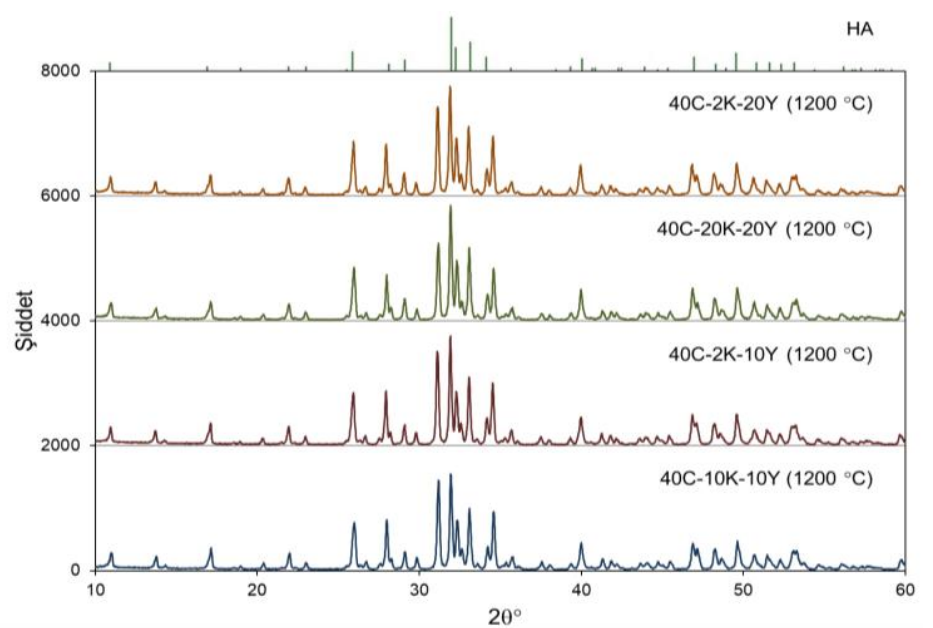

Şekil 4. Farklı karıştırma ve yaşlandırma süreleri uygulanarak üretilen ve $1200{ }^{\circ} \mathrm{C}$ 'de 1 sıll işleme tabi tutulan HA tozlarına ait XRD spektrumları

\subsection{Karıştırma ve Yaşlandırma Parametrelerinin Üretilen HA Tozlarının Parçacık Boyutları ve Toz Morfolojilerine Etkilerinin Belirlenmesi}

Yürütülen çalışmada sentezlenen ve kaplama amacıyla kullanılan HA tozlarının parçacık boyutları ve toz morfolojilerinin belirlenmesi amacıyla parçacık boyutu analizleri ve SEM incelemeleri gerçekleştirilmiştir.

Parçacık boyutu analizi, tek bir toz parçacığının boyutundan ziyade birden fazla toz parçacığından oluşan bir topaklanmanın boyutu ile ilgili bilgi vermektedir. Parçacık boyutu analiz sonuçları (Çizelge 2) ile numunelerin SEM görüntülerinin (Şekil 5) karşılaştırılması sonucunda, parçacık boyutu analiz sonuçlarının, elde edilen SEM görüntülerinde gözlemlenen primer parçacık değerlerinden daha büyük olduğu görülmektedir. $\mathrm{Bu}$ durum, elde edilen tozların topaklanma eğiliminde olduklarını göstermektedir.

Çizelge 2. Farklı üretim parametreleri kullanılarak elde edilen HA tozlarının parçacık boyutları

\begin{tabular}{|c|c|}
\hline Numune Ad1 & Parçacık Boyutu (nm) \\
\hline 40C-2K-2Y & 83,3 \\
\hline 40C-2K-10Y & 105,0 \\
\hline 40C-10K-10Y & 125,0 \\
\hline 40C-2K-20Y & 101,0 \\
\hline 40C-20K-20Y & 76,4 \\
\hline
\end{tabular}

2 gün süreyle karıştırılan ve yaşlandırılan numune ile (40C-2K-2Y) ile 20 gün süreyle karıştırılan ve yaşlandırılan numunenin (40C-20K-20Y) SEM 
görüntüleri, artan karıştırma ve yaşlandırma süreleri ile primer parçacık boyutunun belirgin biçimde arttığını göstermektedir (Şekil 5). Ancak bu iki numunenin parçacık boyutu analizleri (Çizelge 2), artan karıştırma ve yaşlandırma sürelerinin parçacık boyutunda bir azalmaya yol açtığına işaret etmektedir. Bu bulgudan hareketle, artan karıştırma ve yaşlandırma sürelerinin, tozların topaklanma eğilimini azalttığı sonucuna ulaşılmıştır.
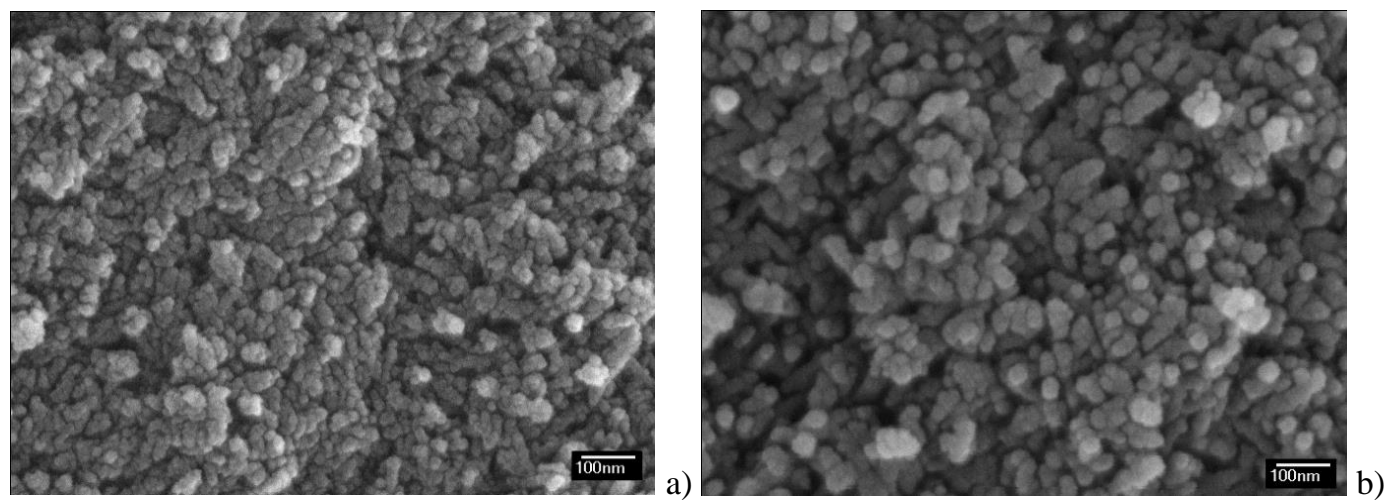

Şekil 5. Üretilen tozların SEM görüntüleri; a. 2 gün karıştırma ve yaşlandırma (40C-2K-2Y); b. 20 gün karıştırma ve yaşlandırma (40C-20K-20Y)

Ayrıca artan karıştırma ve yaşlandırma süreleri ile tozların daha küresel hale geldiği görülmüştür. Bu nedenle; homojen bir kaplama eldesi açısından önemli olan küresel biçimli ve düşük topaklanma eğilimine sahip tozların üretilmesinde karıştırma ve yaşlandırma işlemlerinin uygulanmasının önemli olduğu düşünülmektedir.

\subsection{Kaplamada Kullanılacak Olan Süspansiyon için Uygun pH Değerinin Belirlenmesi}

Başarılı bir kaplama eldesinde, kaplama işlemi sırasında kullanılan süspansiyonun zeta potansiyelinin mutlak değerinin $30 \mathrm{mV}$ 'dan yüksek seviyede olması önem taşımaktadır.

$\mathrm{Bu}$ amaçla, kaplamada kullanılacak olan süspansiyonun zeta potansiyel değerinin belirlenmesine yönelik yapılan ölçümlerde, süspansiyonun zeta potansiyelinin $\mathrm{pH}$ 3,5-4,0 arasında mutlak değer $30 \mathrm{mV}$ 'un üzerinde olduğu belirlenmiş ve bu iki $\mathrm{pH}$ değeri arasında yaklaşık $40 \mathrm{mV}$ zeta potansiyeli elde edilmiştir. Yapılan ölçüler sonucunda kaplamada kullanılacak olan süspansiyonların zeta potansiyel değeri göz önüne alınarak, kaplama süspansiyonların $\mathrm{pH}$ değerleri 3,5-4,0 aralığında olacak şekilde ayarlanmıştır.

\section{6. Üretim Așamasında Kullanılan Karıștırma ve Yaşlandırma Parametrelerinin, Kaplamada Çatlak Oluşumuna Etkisinin Belirlenmesi}

Çalışma kapsamında sentezlenen HA tozları, elektroforetik depozisyon yöntemi ile Ti6Al4V metal yapilar üzerine kaplanarak sentezleme aşamasında kullanılan karıştırma ve yaşlandırma parametrelerinin elde edilen kaplamalardaki çatlak oluşumuna etkisinin belirlenmesi amacıyla kaplama yüzeylerinde SEM incelemesi yapılmıştır. $\mathrm{Bu}$ inceleme sonucunda; karıştırma ve yaşlandırma süreleri arttıkça elde edilen kaplamalarda oluşan çatlakların boyutlarının azaldı ğı belirlenmiştir. 2 gün karıştırılan ve 2 gün yaşlandırılan (40C-2K-2Y) HA tozu ile elde edilen kaplamalarda diğer HA tozları ile elde edilen kaplamalara kıyasla belirgin biçimde büyük çatlakların oluştuğu gözlenmiştir (Şekil 6.a-e). 2 günden daha uzun süre karıştırılan ve yaşlandırılan HA tozları (40C-2K-10Y, 40C-10K$10 \mathrm{Y}, 40 \mathrm{C}-2 \mathrm{~K}-20 \mathrm{Y}$ ve $40 \mathrm{C}-20 \mathrm{~K}-20 \mathrm{Y})$ arasinda çatlak oluşumu ve çatlak boyutları açısından belirgin bir farka rastlanmamıştır (Şekil 6.b-e). 
Üretim Parametrelerinin Hidroksiapatit Tozlarının Özellikleri ve Kaplama Kalitesi Üzerindeki Etkilerinin Incelenmesi

a.
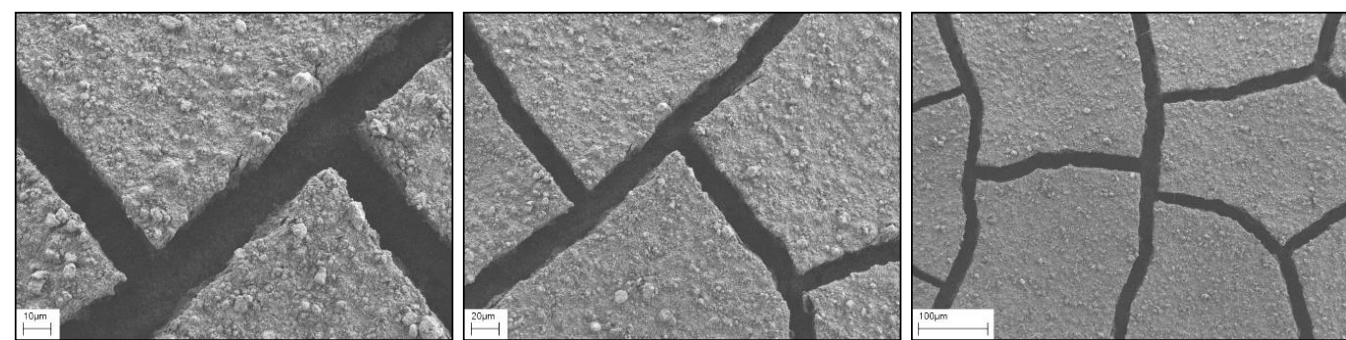

b.
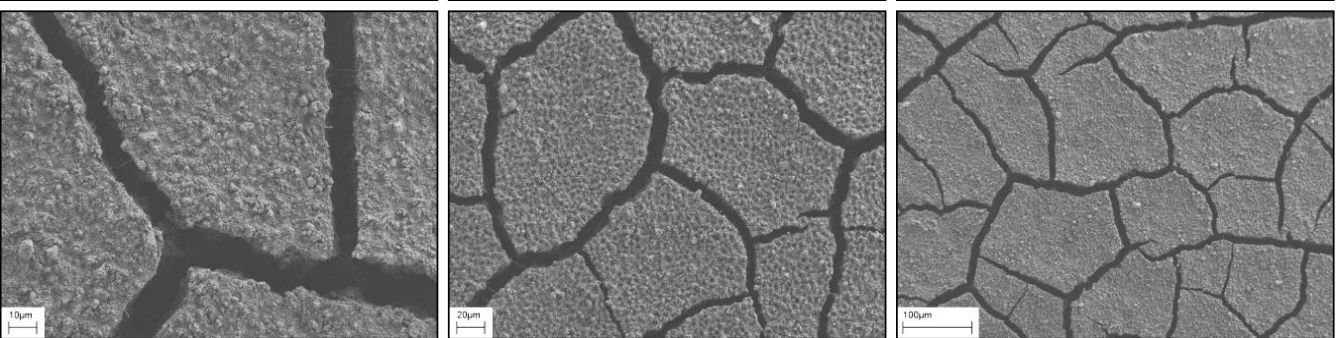

c.
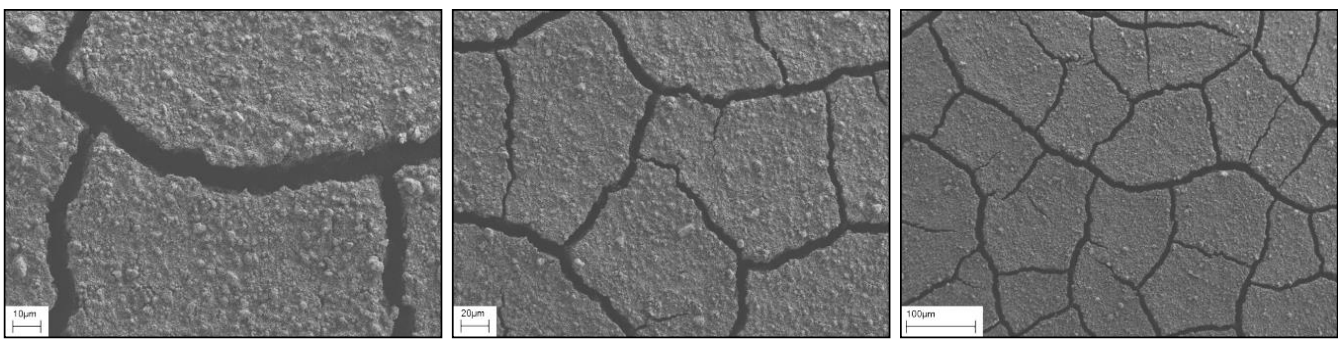

d.
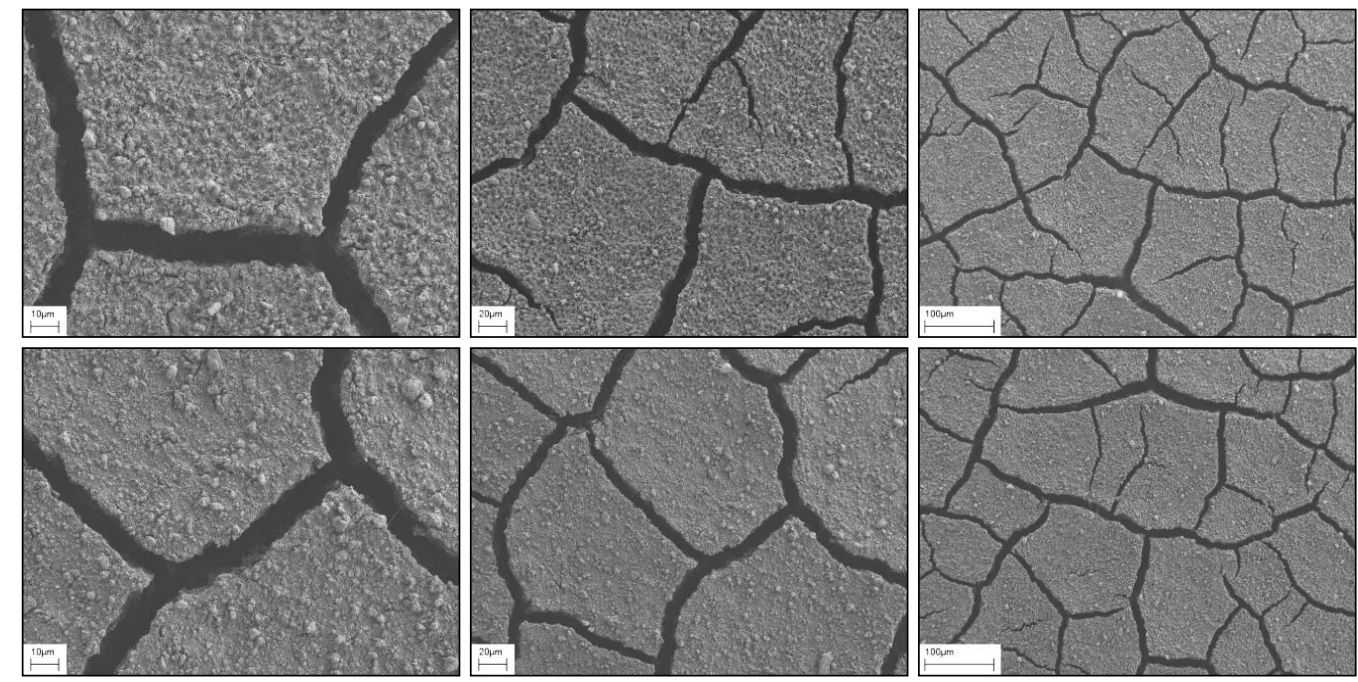

Şekil 6. Farklı karıştırma ve yaşlandırma süreleri uygulanarak elde edilen HA tozlarına ait farklı büyütmelerde (sol sütun: $2000 \mathrm{X}$, orta sütun: $1000 \mathrm{X}$, sağ sütun: $500 \mathrm{X}$ ) elde edilmiş SEM görüntüleri: a. 2 gün karıştırma ve 2 gün yaşlandırma (40C-2K-2Y); b. 2 gün karıştırma ve 10 gün yaşlandırma (40C-2K-10Y); c. 10 gün karıştırma ve 10 gün yaşlandırma (40C-10K-10Y); d. 2 gün karıştırma ve 20 gün yaşlandırma (40C-2K-20Y); e. 20 gün karıştırma ve 20 gün yaşlandırma (40C-20K-20Y) 
Farklı karıştırma süreleri ve aynı yaşlandırma süreleri uygulanarak üretilen HA tozları ile elde edilen kaplamalarının SEM görüntülerinin karşılaştırılması neticesinde, farklı karıştırma sürelerinin çatlak oluşumunda belirleyici bir rol oynamadığı görülmüştür. Diğer yandan, aynı karıştırma süreleri ve farklı yaşlandırma süreleri uygulanarak üretilen HA tozları ile elde edilen kaplamalarının SEM görüntülerinin karşılaştırılması sonucunda, yaşlandırma süresinin 2 günden 10 güne çıkarılmasıly çatlaklarda belirgin bir azalma tespit edilmiştir.

Ancak devamında yaşlandırma süresinin 20 güne çıkarılması ile kayda değer bir farklılık saptanmamıştır. $\mathrm{Bu}$ nedenle, 10 günlük yaşlandırma süresinin kaplamalarda kullanılacak toz üretimine uygun olduğu, daha uzun süreli yaşlandırma işleminin çatlak boyutları açısından anlamlı bir fark ortaya koymadığ düşünülmektedir.

\section{TARTIŞMA VE SONUÇ}

HA sentezlenmesi sirasinda $40,60,80$ ve $100{ }^{\circ} \mathrm{C}$ olarak uygulanan reaksiyon sicaklıklarının, faz oluşumu ve yüksek sıcaklık kararlılığına etkilerinin belirlenmesi amaciyla, elde edilen numuneler sentezleme sonrası ve 1000 ve $1200{ }^{\circ} \mathrm{C}$ 'de yapılan 1 sıl işlem sonrası XRD analizine tabi tutularak bozunma olup olmadığı incelenmiştir. Bu iki sıcaklıkta gerçekleştirilen 1sıl işlem sonrasında HA'in faz kompozisyonunda belirgin bir fark oluşmadığı gözlemlenmiştir. Ancak $1200{ }^{\circ} \mathrm{C}$ 'de gerçekleştirilen isıl işlem sonrasına XRD analizlerinde gözlemlenen az belirgin TCP pikleri, artan 1sıl işlem sıcaklığının HA'in yüksek sıcaklık kararlılığını etkilediğini göstermektedir. $\mathrm{Bu}$ nedenle, kaplama dayanımını arttırmak için gerçekleştirilen sinterleme işleminin, bağlanma dayanımını arttırmaya yetecek ancak HA'in TCP'ye dönüşmesini engelleyecek sicaklıklarda gerçekleştirilmesinin uygun olacağ sonucuna ulaşılmıştır. Ayrıca, sentezleme aşamasında kullanılan sıcaklıkların faz oluşumuna bariz bir etkisi olmadığı belirlenmiş olup, çalışmanın geri kalan kısmında sentezleme sıcaklığı olarak $40{ }^{\circ} \mathrm{C}$ sıcaklık kullanılmıştır.
Sentezleme aşamasında kullanılan karıştırma ve yaşlandırma işlemlerinin, elde edilen HA'in faz oluşumlarına ve toz morfolojisine etkilerinin belirlenmesi amaciyla sentez reaksiyonunun gerçekleştirilmesinin ardından süspansiyon içerisinde $40^{\circ} \mathrm{C}$ 'de 2,10 ve 20 gün boyunca yaşlandırma işlemi uygulanmış, ayrıca karıştırma işlemi 2 günün ardından durdurulmuş veya tüm yaşlandırma süresince sürdürülmüştür. Elde edilen tüm numunelerin XRD incelemelerinde karakteristik HA pikleri saptanmış olup, belirgin başka bir faza rastlanmamıştır.

Elde edilen HA tozlarının yüksek sıcaklık altında kararlılıklarını belirlemek amacıyla yapılan XRD incelemelerinde, $1200{ }^{\circ} \mathrm{C}$ 'ye isitilan numunelerde ana faz olan HA'in yanı sıra sıcaklığa bağlı olarak TCP oluşumu gözlenmiştir. HA'in yüksek sıcaklıkta TCP'ye bozunması açısından incelendiğinde farklı karıştırma ve yaşlandırma parametreleri kullanılarak üretilen tozlar arasında belirgin bir farklılığa rastlanmamıştır.

Tozlar üzerinde gerçekleştirilen SEM incelemelerinde kullanilan parametrelerden bağımsız olarak, yaklaşık $50 \mathrm{~nm}$ boyutlarında küresel biçimli primer parçacıklardan oluşan tozlar üretilebildiği görülmüştür. Yaşlandırma süresinin artmasıyla parçacık boyutlarında artış olduğu saptanmıştır. $\mathrm{Bu}$ bulgu, gerçekleştirilecek uygulamaya uygun boyutta küresel boyutta HA tozu eldesi amaciyla yaşlandırma süresinin kullanılmasının uygun bir yöntem olduğunu göstermektedir.

2 gün süresince karıştırılan ve yaşlandırılan HA tozları ile elde edilen kaplamalarda oluşan çatlakların, daha uzun süreli yaşlandırma ve karıştırma süreleri uygulanarak üretilen tozlar ile elde edilen kaplamalarda oluşan çatlaklara kıyasla daha büyük oldukları belirlenmiştir. Buna karşın, 10 gün ve 20 günlük yaşlandırma işlemleri ile elde edilen tozlarla üretilen kaplamalar arasında çatlak oluşumu açısından kayda değer bir farka rastlanmamıştır. $\mathrm{Bu}$ bulgu; çatlak oluşumunun kontrol edilmesi açısından, karıştırma ve yaşlandırma sürelerinin arttırılmasının çatlak oluşumunu azaltmada olumlu etki yaptığını göstermektedir. Diğer yandan, 10 ve 20 günlük 
yaşlandırma işlemleri arasında çatlak oluşumu açısından bariz bir fark tespit edilememiş olması nedeniyle, 10 günlük yaşlandırma süresinin, daha az çatlak oluşumuna imkan veren HA tozu üretimi açısından yeterli olduğu düşünülmektedir.

\section{TEŞEKKÜR}

Bu çalışma Mersin Üniversitesi Bilimsel Araştırma Projeleri tarafindan "BAP-MÜH F MM (ÖA) 2010-5 A” proje numarasıyla desteklenmiştir.

\section{KAYNAKLAR}

1. Brunski, J. B., 2004. Biomaterials Science: An Introduction to Materials in Medicine. B.D. Ratner, A.S. Hofman, F.J. Schoen, J.E. Lemons (editör). Academic Press, California, 137-153.

2. Albayrak, O., Oncel, C., Tefek, M., Altintas, S., 2007. Effects of Calcination on the Electrophoretic Deposition of Naturally Derived and Chemically Synthesized Hydroxyapatite. Reviews on Advanced Materials Science, 15, 10-15.

3. Gil, F.J., Padros, A., Manero, J.M., Aparicio, C., Nilsson, M., Planell, J.A., 2002. Growth of Bioactive Surface on Titanium and its Alloys for Orthopedic and Dental Implants. Materials Science and Engineering C, 22, 53-60.

4. Gomez-Vega, J.M., Saiz, E., Tomsia, A.P., Oku, T., Suganuma, K., Marshall, G.W., Marshall, S.J., 2000. Novel Bioactive Functionally Graded Coatings on Ti6Al4V. Advanced Materials, 12, 894-898.

5. Ma, J., Liang, C.H., Kong, L.B., Wang, C., 2003. Colloidal Characterization and Electrophoretic Deposition of Hydroxyapatite on Titanium Substrate. Journal of Materials Science: Materials in Medicine, 14, 797-801.

6. Mostafa, N.Y., 2005. Characterization, Thermal Stability and Sintering of Hydroxyapatite Powders Prepared by Different Routes. Materials Chemistry and Physics, 94, 333-341.

7. Yang, Z., Jiang, Y., Wang, Y.J., Ma, L.Y., Li, F., 2004. Preparation and Thermal Stability Analysis of Hydroxyapatite Derived from the Precipitation Process and Microwave
Irradiation Method. Materials Letters, 58, 3586-3590.

8. Sung, Y.M., Lee, J.C., Yang, J.W., 2004. Crystallization and Sintering Characteristics of Chemically Precipitated Hydroxyapatite Nanopowder. Journal of Crystal Growth, 262, 467-472.

9. Jalota, S., Tas, C., Bhaduri, S.B., 2004. Microwave-Assisted Synthesis of Calcium Phosphate Nanowhiskers. Journal of Materials Research, 19(6), 1876-1881.

10. Albayrak, O., 2016. Structural and Mechanical Characterization of Boron Doped Biphasic Calcium Phosphate Produced by Wet Chemical Method and Subsequent Thermal Treatment. Materials Characterization, 113, 82-89.

11. Kong, L.B., Ma, J., Boey, F., 2002. Nanosized Hydroxyapatite Powders Derived from Coprecipitation Process. Journal of Materials Science, 37, 1131-1134.

12. Kumta, P.N., Sfeir, C., Lee, D.H., Olton, D., Choi, D., 2005. Nanostructured Calcium Phosphates for Biomedical Applications: Novel Synthesis and Characterization. Acta Biomaterialia, 1, 65-83.

13. Kweh, S.W.K., Khor, K.A., Cheang, P., 1999. The Production and Characterization of Hydroxyapatite (HA) Powders. Journal of Materials Processing Technology, 89-90, 373-377.

14. Nagai, H., Nishimura, Y., 1980. Hydroxyapatite, Ceramic Material and Process for Preparing Thereof. A.B.D. Patenti, Patent No: 4330514.

15. Albayrak, O., Ugurlu, M., 2016. Bor Katk1l1 Hidroksiapatit Üretimi ve Karakterizasyonu: Bor Oranı ve Sinterleme Sıcaklığının Yapı ve Mekanik Özellikler Üzerindeki Etkisi. Journal of the Faculty of Engineering and Architecture of Gazi University, 31, 749-761.

16. Afshar, A., Ghorbani, M., Ehsani, N., Saeri, M. R., Sorrell, C.C., 2003. Some Important Factors in the Wet Precipitation Process of Hydroxyapatite. Materials and Design, 24, 197-202.

17. Saeri, M.R., Afshar, A., Ghorbani, M., Ehsani, N., Sorrell, C.C., 2003. The Wet Precipitation Process of Hydroxyapatite. Materials Letters, 57, 4064-4069. 
18. Wei, M., 1997. Electrophoresis of Hydroxyapatite on Metal Substrates. Doktora Tezi, University of New South Wales, 232.

19. Boccaccini, A.R., Keim, S., Ma, R., Li, Y., Zhitomirsky, I., 2010. Electrophoretic Deposition of Biomaterials. Journal of the Royal Society Interface, 7, 581-613.

20. Fukada, Y., Nagarayan, N., Mekky, W., Bao, Y., Kim, H.S., Nicholson, P.S., 2004. Electrophoretic Deposition-Mechanisms, Myths and Materials. Journal of Materials Science, 39, 787-801.

21. Suzdal'tsev, E.I., Kharitonov, D.V., 2004. Methods for the Electrophoretic Shaping of Ceramic Products from Aqueous Slips of Inorganic Materials (a Review). Refractories and Industrial Ceramics, 45, 42-47.

22. Sena, L.A., Andrade, M.C., Rossi, A.M., Soares, G.A., 2002. Hydroxyapatite Deposition by Electrophoresis on Titanium Sheets with Different Surface Finishing. Journal of Biomedical Materials Research, 60, 1-7.

23. Wei, M., Ruys, A.J., Milthorpe, B.K., Sorrell, C.C., Evans, J.H., 2001. Electrophoretic Deposition of Hydroxyapatite Coatings on Metal Substrates: A Nanoparticulate DualCoating Approach. Journal of Sol-Gel Science and Technology, 21, 39-48.

24. Sridhar, T.M., Mudali, U.K., Subbaiyan, M., 2003. Sintering Atmosphere and Temperature Effects on Hydroxyapatite Coated Type $316 \mathrm{~L}$ Stainless Steel. Corrosion Science, 45, 2337-2359.

25. Wei, M., Ruys, A.J., Milthorpe, B.K., Sorrell, C.C., 2005. Precipitation of Hydroxyapatite Nanoparticles: Effects of Precipitation Method on Electrophoretic Deposition. Journal of Materials Science: Materials in Medicine, 16, 319-324. 
